\title{
Should Authors Submit Previous Peer-Review Reports When Submitting Research Papers? Views of General Medical Journal Editors
}

\author{
Jochen W. L. Cals, MD, PbD ${ }^{1}$ \\ Christian D. Mallen, BMBS, \\ MRCGP, $P b D^{2}$ \\ Liam G. Glynn, MD, FRCGP, \\ $\mathrm{FRCSI}^{3}$ \\ Daniel Kotz, $P b D^{1}$ \\ 'Department of General Practice, CAPHRI \\ School for Public Health and Primary Care, \\ Maastricht University, Maastricht, the \\ Netherlands \\ ${ }^{2}$ Arthritis Research UK Primary Care Cen- \\ tre, University of Keele, Keele, Stafford- \\ shire, United Kingdom \\ ${ }^{3}$ Discipline of General Practice, National \\ University of Ireland, Galway, Ireland
}

Conflict of interest: authors report none.

\section{CORRESPONDING AUTHOR}

Jochen W. L. Cals, MD, PhD

PO Box 616

6200 MD Maastricht

The Netherlands

j.cals@maastrichtuniversity.nl

\begin{abstract}
Publishing research can be time consuming, as papers are often submitted and reviewed by multiple journals before final acceptance. We hypothesized that attaching previous peer-review reports to the next submission of the paper to a different journal (possibly with point-to-point responses and amendments) could decrease the workload for both reviewers and editors and could shorten the time from final draft to actual publication. We therefore performed an online survey to assess the views of the editors-in-chief of all 100 general medical journals from the citation impact factor report category "internal \& general medicine" (ISI Web of Knowledge). Of contacted editors, $61 \%$ responded. One of 4 journals do currently receive peer-review reports on occasion. Editors recognized potential advantages but also concerns on using previous peer-review reports across 3 themes: scientific community, quality of papers, and the publication process. The use of previous peer-review reports has the potential to facilitate authors, reviewers, and editors in optimizing peer review in general medical science.
\end{abstract}

Ann Fam Med 2013;11:179-181. doi:10.1370/afm.1448.

\section{INTRODUCTION}

$\mathrm{P}$ eer review imposes a considerable burden on authors, reviewers, and editors in the scientific community. ${ }^{1}$ The process from completing the final draft of a research paper to its ultimate publication can be long and may traverse many submission systems, as well as editors' and reviewers' desks. Peer review is at the heart of the scientific publishing process, but many defects have been claimed. ${ }^{2}$ Although reviewers are asked to evaluate a paper on its merits, journal editors must assess these reviews and make a decision about the suitability of a particular paper for their journal.

Journals often state in decision letters that they receive many more papers than they can ever publish and often have to reject valuable and worthwhile work based on editorial scope, standards, and limited space. A paper that was rejected by a specific journal after having gone through peer review can still be suitable for publication in a different journal. Yet journals are often unaware of the presubmission history of a paper, including potentially useful peer-review reports. Authors may be hesitant to include these reports, as it is not common practice in the traditional peer-review system, and by so doing, authors may feel that it will decrease chances of acceptance if the paper was not acceptable for a previous journal. We hypothesized that attaching previous peer-review reports to the next submission of the paper to a different journal (possibly with point-to-point responses and amendments) could decrease the workload for both reviewers and editors and could shorten the time from final draft to actual publication. We therefore performed an online survey to assess the views of the editors of all general medical journals on 
including previous peer-review reports with the new submission of a research paper.

\section{METHODS}

We selected all journals from the 2007 citation impact factor report category "internal \& general medicine" (ISI Web of Knowledge). ${ }^{3}$ We contacted the editorsin-chief from each journal through e-mail in 2010 and invited them to participate in a short online survey (using SurveyMonkey software), with 2 e-mail reminders for nonresponders, if applicable. We asked 12 short questions addressing the journal's current peer-review process and the existence of a policy on the use of previous peer-review reports (with yes/no and 5-point Likert scale options). The survey was routed to prevent respondents being asked unnecessary questions.

Using open-ended questions (What do you think may be important advantages/important drawbacks of submitting previous peer reviews with the current submission? Do you have any other comments you would like to share with us on the use of previous peer review reports?), we also explored the editors' thoughts on the perceived advantages and disadvantages of using previous peer-review reports in the editorial process. We calculated rates and means for the closed-ended questions and performed a framework analysis on the open-ended questions to build a SWOT (strengths, weaknesses, opportunities, threats) analysis of the use of previous peer-review reports. The framework analysis consisted of familiarization with the data, indexing the material, charting, and interpretation to inform the key themes. Themes were shared and debated by all 4 researchers to reach a concordance of views on common themes.

\section{RESULTS}

Of the 100 journals identified, we could contact 83 (15 journal had no available or working e-mail address, 2 were excluded because they had no peer-review process). Of these, 51 journals (61\%) participated in our survey. Response rates were 48\% (14 of 29) for journals with the highest impact factors (greater than 2), 76\% (23 of 30 ) for those with medium impact factors (between 1 and 2) and $58 \%$ (14 of 24) for journals with low impact factors less than 1). Eighty percent of respondents were editors-in-chief, the remaining were other members of the editorial board. Journals commissioned a median of 2 reviewers $(I Q R=1)$ per original paper, for which a median of 4.5 reviewers $(I Q R=3.5)$ needed to be invited. Of interest, $23 \%$ of journals already received previous peer-review reports on occasions. Only 9 journals (18\%) had an explicit policy within the editorial board on the use of these reports, whereas only 3 journals $(6 \%)$ mentioned these in their author guidelines. Those journals with a policy in place all attempted to use previous peer-review reports in their review process, but in most cases they still invite regular reviewers. Just under one-half (49\%) of all editors said they would encourage authors to submit previous peer-review reports with their submission in the future.

Table 1 gives the journals' views on previous peerreview reports and their likely consequences on work-

Table 1. General Medical Journal Editors' Views on Previous Peer-Review Reports

\begin{tabular}{|c|c|c|c|c|}
\hline Journal Editors' Views & $\begin{array}{l}\text { YesIAgree } \\
\text { No. }(\%)\end{array}$ & $\begin{array}{l}\text { No/Disagree } \\
\text { No. }(\%)\end{array}$ & $\begin{array}{l}\text { Indecisive } \\
\text { No. (\%) }\end{array}$ & $\begin{array}{l}\text { NA } \\
\text { No. }\end{array}$ \\
\hline \multicolumn{5}{|l|}{ General statements of the history of a paper } \\
\hline $\begin{array}{l}\text { Would you like authors to indicate whether a paper has been } \\
\text { previously submitted? }\end{array}$ & $22(45)$ & $12(24)$ & $15(31)$ & 2 \\
\hline $\begin{array}{l}\text { Would you like authors to indicate where a paper has been } \\
\text { previously submitted? }\end{array}$ & $15(31)$ & $15(31)$ & $19(39)$ & 2 \\
\hline \multicolumn{5}{|l|}{ General statements on previous submissions } \\
\hline We would like to know from which journal(s) the peer reviews originate & $28(68)$ & $7(17)$ & $6(15)$ & 10 \\
\hline We would like to see point-to-point response to the comments & $32(78)$ & $6(15)$ & $3(7)$ & 10 \\
\hline Submission of previous peer reviews should be obligatory in the future & $6(15)$ & $19(46)$ & $16(39)$ & 10 \\
\hline \multicolumn{5}{|l|}{ Submission of peer-review reports will have the following effect } \\
\hline $\begin{array}{l}\text { Decrease the number of commissioned reviewer reports to reach } \\
\text { a decision for that specific paper }\end{array}$ & $15(37)$ & $11(26)$ & $15(37)$ & 10 \\
\hline Decrease workload for the editorial team & $15(36)$ & $17(40)$ & $10(24)$ & 9 \\
\hline Decrease workload for reviewers in general & $20(48)$ & $11(26)$ & $11(26)$ & 9 \\
\hline Make submission processes more transparent & $25(60)$ & $8(19)$ & $9(21)$ & 9 \\
\hline Decrease time to decision & $17(40)$ & $12(29)$ & $13(31)$ & 9 \\
\hline
\end{tabular}


Table 2. Strengths, Opportunities, Weaknesses, and Threats of Using Previous Peer-Review Reports With Next Submission, as Expressed by General Medical Journal Editors

\begin{tabular}{lll}
\hline Theme & Strengths and Opportunities & Weaknesses and Threats \\
\hline Scientific community & $\begin{array}{l}\text { Decrease workload for reviewers } \\
\text { Enhance review process as a whole } \\
\text { Improve transparency of reviewing process }\end{array}$ & $\begin{array}{l}\text { Create lazy reviewers and editors } \\
\text { Prohibit manuscript to receive an objective fresh start }\end{array}$ \\
Quality of papers & $\begin{array}{l}\text { Improve scientific quality of papers } \\
\text { Raise potential issues overlooked by new reviewers }\end{array}$ & $\begin{array}{l}\text { Create reluctance of authors to submit unfavorable } \\
\text { reviews }\end{array}$ \\
Publication process & Have a shorter time to decision & Have a longer time to decision \\
& Decrease workload for reviewers & Submission management difficulties \\
& Avoid duplication of efforts &
\end{tabular}

load and transparency of the publication process. Three main themes emerged from the analysis of the closed and open-ended questions: scientific community, quality of papers, and the publication process. Editors identified advantages of using previous peer-review reports across all 3 themes, but they also expressed concerns. The opportunities mostly related to decreasing the workload of reviewers (including avoidance of duplication), improved transparency and quality of papers, and a potential faster editorial and publication process. Expressed threats were the introduction of bias when forwarding positive and excluding negative previous peer-review reports and that using these reports may make it difficult for the paper to have an objective new start. Table 2 presents the perceived SWOT of using previous peer-review reports across the 3 themes.

\section{CONCLUSIONS}

Editors of general medical journals have diverging views on the use of previous peer-review reports in submission of scientific papers. One of 4 journals currently receive these reports on occasion. Although one-half of the journal editors would encourage submission of previous peer-review reports, few journals currently mention the possibility in author guidelines. Evaluating and rethinking the reviewing system to decrease reviewers' workload seems crucial, especially because reviewers performance varies in quality and seems to deteriorate over time. ${ }^{4,5}$ Strategies to optimize the quality of review reports, such as masking author identity or providing open peer review, have failed. ${ }^{6,7}$ With the 7 th International Congress on Peer Review and Biomedical Publication upcoming in $2013,{ }^{8}$ we hope that this survey will stimulate debate on how to improve the review system. The use of previous peer-review reports has the potential to facilitate authors, reviewers, and editors and to help to seek for new opportunities to optimize peer review in general medical science.

To read or post commentaries in response to this article, see it online at http://www.annfammed.org/content/11/2/179.

Key words: peer review; publishing

Submitted March 26, 2012; submitted, revised, July 13, 2012; accepted August 8, 2012.

Author contributions: Jochen Cals coordinated the study and wrote the first manuscript. All authors were involved in the design of the study, the collection and analysis of data, and writing of this report. The authors have no previous peer-review reports to declare.

Acknowledgments: The idea for this study was conceived during the residential meeting of the Brisbane Initiative, which is now named the International Primary Care Leadership Programme, hosted by the University of Oxford, UK (http://www.phc.ox.ac.uk/events/ international-primary-care-research-leadership-programme).

\section{References}

1. Godlee F, Jefferson T. Peer Review in Health Sciences. London: BMJ Books; 2003.

2. Smith R. Peer review: a flawed process at the heart of science and journals. J R Soc Med. 2006;99(4):178-182.

3. Thompson Rueters. Web of Knowledge [website]. http://wokinfo. $\mathrm{com} /$.

4. Callaham M, McCulloch C. Longitudinal trends in the performance of scientific peer reviewers. Ann Emerg Med. 2011;57(2):141-148.

5. Baxt WG, Waeckerle JF, Berlin JA, Callaham ML. Who reviews the reviewers? Feasibility of using a fictitious manuscript to evaluate peer reviewer performance. Ann Emerg Med. 1998;32(3 Pt 1):310-317.

6. Justice $A C$, Cho MK, Winker MA, Berlin JA, Rennie D; PEER Investigators. Does masking author identity improve peer review quality? A randomized controlled trial. JAMA. 1998;280(3):240-242.

7. Van Rooyen S, Godlee F, Evans S, Smith R, Black N. Effect of blinding and unmasking on the quality of peer review. J Gen Intern Med. 1999;14(10):622-624.

8. American Medical Association. The Seventh International Congress on Peer Review and Biomedical Publication [website]. http://www. ama-assn.org/public/peer/peerhome.htm. 